\title{
Overexpression of Thy1 and ITGA6 is associated with invasion, metastasis and poor prognosis in human gallbladder carcinoma
}

\author{
DAN-HUA ZHANG ${ }^{1}$, ZHU-LIN YANG ${ }^{1}$, EN-XIANG ZHOU ${ }^{1}$, XIONG-YING MIAO ${ }^{1}$, QIONG ZOU ${ }^{2}$, \\ JING-HE LI ${ }^{3}$, LU-FENG LIANG ${ }^{4}$, GUI-XIANG ZENG ${ }^{5}$ and SEN-LIN CHEN ${ }^{6}$ \\ ${ }^{1}$ Research Laboratory of Hepatobiliary Diseases, The Second Xiangya Hospital, Central South University, Changsha, \\ Hunan 410011; ${ }^{2}$ Department of Pathology, Changde Central Hospital, Changde, Hunan 415000; \\ ${ }^{3}$ Department of Pathology, Basic Medical Science College, Central South University, Changsha, Hunan 410011; \\ ${ }^{4}$ Department of Hepatobiliary and Pancreatic Surgery, Hunan Provincial People's Hospital, Changsha, Hunan 410007; \\ ${ }^{5}$ Department of Pathology, Loudi Central Hospital, Loudi, Hunan 417011; \\ ${ }^{6}$ Department of Pathology, Hunan Provincial Tumor Hospital, Changsha, Hunan 410013, P.R. China
}

Received June 14, 2015; Accepted October 14, 2016

DOI: $10.3892 / 01.2016 .5341$

\begin{abstract}
Gallbladder cancer (GBC) is a rare but highly aggressive cancer for which no well-accepted prognostic biomarkers have been identified. Thymus cell antigen 1 (Thy1), also known as cluster of differentiation (CD)90, and integrin a6 (ITGA6), also known as CD49f, are important molecules in cancer and putative markers of various stem cell types. However, their role in GBC remains to be elucidated. In the present study, Thy1 and ITGA6 expression status in clinical GBC samples, which comprised squamous cell/adenosquamous carcinoma (SC/ASC) and adenocarcinoma (AC) subtypes, was investigated. The associations between Thy1 and ITGA6 expression and clinical parameters and survival rate were analyzed separately. The THY1 and ITGA6 messenger RNA levels were significantly higher in both SC/ASC and AC tissues than in adjacent non-tumor tissues (all $\mathrm{P}<0.001$ ). These results were subsequently confirmed by immunohistochemical analyses. Overexpression of Thyl and ITGA6 was correlated with poor differentiation, large tumor size, lymph node metastasis and great invasiveness in SC/ASC (Thy1, $\mathrm{P}=0.045, \mathrm{P}=0.005, \mathrm{P}=0.003$ and $\mathrm{P}=0.009$, respectively, and ITGA6, $\mathrm{P}=0.029, \mathrm{P}=0.011, \mathrm{P}=0.009$ and $\mathrm{P}=0.004$, respectively) and $\mathrm{AC}$ (Thy1, $\mathrm{P}=0.027, \mathrm{P}<0.001, \mathrm{P}=0.003$ and $\mathrm{P} 0.004$, respectively, and ITGA6, $\mathrm{P}=0.002, \mathrm{P}=0.003, \mathrm{P}=0.006$ and $\mathrm{P}=0.006$, respectively). Both Thy1 and ITGA6 were expressed at higher levels in AC with advanced tumor-node-metastasis
\end{abstract}

Correspondence to: Dr Zhu-Lin Yang, Research Laboratory of Hepatobiliary Diseases, The Second Xiangya Hospital, Central South University, 139 Renmin Middle Road, Changsha, Hunan 410011, P.R. China

E-mail: yangzhulin8@sina.com

Key words: Thy1, ITGA6, gallbladder carcinoma, prognostic markers stage (TNM) than in AC with low TNM stage $(\mathrm{P}=0.001$ and $\mathrm{P}=0.018$, respectively). In addition, patients with elevated Thy1 or ITGA6 expression had shorter overall survival than those with negative Thy1 or ITGA6 expression. Multivariate Cox regression analysis demonstrated that Thy1 (SC/ASC, $\mathrm{P}=0.001$ and $\mathrm{AC}, \mathrm{P}=0.005$ ) and ITGA6 (both $\mathrm{P}=0.003$ ) were independent predictors of poor prognosis in both SC/ASC and AC patients. In conclusion, Thy1 and ITGA6 could be clinical prognostic markers for GBC.

\section{Introduction}

Gallbladder cancer (GBC) is the most common malignancy of the biliary tract. The major subtype of GBC is adenocarcinoma (AC), which accounts for $>90 \%$ of GBC cases (1), while squamous cell/adenosquamous carcinoma (SC/ASC) is a rare subtype, comprising 1.4-10.4\% of GBC cases (2). Notably, the 5-year survival of patients with GBC involving these two subtypes is extremely low. Their nonspecific symptomatology results in advanced disease at the time of presentation, contributing to poor prognosis and decreased survival (2). Thus, it is urgent to identify biomarkers for the diagnosis and prognosis of this disease. However, the genetic and molecular alterations in GBC are still poorly understood. In addition, its rarity renders the collection of large sample cohorts difficult.

Thymus cell antigen 1 (Thy1), also known as cluster of differentiation (CD)90, is a 25-37-kDa glycophosphatidylinositol-anchored protein that is expressed in numerous cell types, including $\mathrm{T}$ cells, neurons, endothelial cells, fibroblasts and numerous tumor cells. Functioning as an important regulator of cell-cell and cell-matrix interactions (3), Thy1 has also been proposed to be an important molecule in cancer. It is overexpressed during prostate cancer progression (4). In hepatocellular carcinoma, increased Thyl expression is associated with the presence of cancer (5). It is noteworthy that Thy1 tends to be expressed in poorly differentiated hepatocellular carcinoma and is associated with poor prognosis $(6,7)$. Consistent with this, male patients with Thyl-positive breast cancer have 
significantly poorer survival than those with Thyl-negative expression (8). In addition, Thy1 promotes migration and metastasis in melanoma (9). Notably, it has been suggested that Thy1 has opposite functions in ovarian (10) and nasopharyngeal cancer (11), where it functions as a tumor suppressor. Nonetheless, the significance of Thyl in the context of GBC remains undetermined.

Integrin $\alpha 6$ (ITGA6), also known as CD49f, is a $150-\mathrm{kDa}$ transmembrane protein. It associates with integrin $\beta 1$ chain (or CD29) to form very late antigen-6, and with integrin $\beta 4$ chain (or CD104) to form the $\alpha 6 \beta 4$ complex, both of which are important laminin receptors (12). Laminin receptors are essential for cell-matrix adhesion and cell-cell interactions. These activate intracellular signaling pathways involved in the regulation of various cellular processes, including cytoskeletal arrangement, growth factor signaling and gene transcription (13). An emerging consensus is that ITGA6 dysregulation is associated with malignancy. An increasing number of studies have revealed that ITGA6 is abnormally expressed in numerous tumors, including breast cancer, lung cancer and liver cancer $(14,15)$. In the majority of these studies, ITGA6 overexpression was significantly associated with tumor cell metastasis and invasion, thus implicating its involvement in tumor progression $(14,15)$. However, no studies have addressed the role of ITGA6 in GBC.

It is worth noting that Thy1 and ITGA6 are putative markers of various cancer stem cells (CSCs) $(6,16-19)$. The proliferation and differentiation of CSCs are dysregulated, and they share characteristics necessary for inducing both tumorigenesis and metastasis. CSCs comprise $\sim 1-5 \%$ of all tumor cells. They are self-renewing and can develop into different cell types to form tumors again, even when the majority of tumor cells have been eliminated (20). Therefore, efficient biomarkers are vital for identifying CSCs. Although the CSC theory is still controversial, CSCs have been identified in multiple solid tumors, including breast cancer (21), hepatocellular carcinoma (22), glioma (16), prostate cancer (4), colorectal cancer (23) and pancreatic cancer (24). However, whether there are CSCs in GBC is not clear. In the present study, the expression of the promising CSC markers Thyl and ITGA6 was evaluated in $46 \mathrm{SC} / \mathrm{ASC}$ and $80 \mathrm{AC}$ patients using reverse transcription-quantitative polymerase chain reaction (RT-qPCR) and immunohistochemical analyses, and Thyl and ITGA6 expression was correlated with the clinical outcome and prognosis of the patients.

\section{Materials and methods}

Patients and tissue specimens. A total of 126 GBC (46 SC/ASC and $80 \mathrm{AC}$ ) samples and paired non-tumor tissue samples were obtained from patients that underwent surgical resection or biopsy between January 1995 and December 2009. The present study was approved by the Central South University Ethics Committee for Human Research from Xiangya Hospital (Changsha, China), The Second Xiangya Hospital (Changsha, China), The Third Xiangya Hospital (Changsha, China), Hunan Provincial People Hospital (Changsha, China), Hunan Provincial Tumor Hospital (Changsha, China), Changde Central Hospital and Loudi Central Hospital (Loudi, China). Written informed consent was obtained from the patients. All samples were
Table I. Clinicopathological characteristics of GBC samples.

\begin{tabular}{lcc}
\hline $\begin{array}{l}\text { Clinicopathological } \\
\text { characteristics }\end{array}$ & $\begin{array}{c}\text { SC/ASC, } \\
\text { no. }(\%)\end{array}$ & $\begin{array}{c}\text { AC, } \\
\text { no. }(\%)\end{array}$ \\
\hline $\begin{array}{l}\text { Gender } \\
\text { Male }\end{array}$ & $19(41.3)$ & $26(32.5)$ \\
Female & $27(58.7)$ & $54(67.5)$ \\
Age, years & & \\
$\leq 45$ & $3(6.5)$ & $16(20.0)$ \\
$>45$ & $43(93.5)$ & $64(80.0)$ \\
$\begin{array}{l}\text { Differentiation } \\
\text { Well }\end{array}$ & & \\
Moderately & $16(34.8)$ & $27(33.8)$ \\
Poorly & $24(52.2)$ & $25(31.3)$ \\
Maximm & $6(13.0)$ & $28(35.0)$
\end{tabular}

Maximum diameter of

tumor, cm

$\begin{array}{lll}\leq 3 & 20(43.5) & 50(62.5) \\ >3 & 26(56.5) & 30(37.5)\end{array}$

Cholecystolithiasis

$(-)$

$18(39.1)$

$42(52.5)$

$(+)$

$28(60.9)$

$38(47.5)$

TNM stage

I+II

$12(26.1)$

$21(26.3)$

III

$20(33.5)$

$38(47.5)$

IV

$14(30.4)$

$21(26.3)$

Lymph node metastasis
$(-)$
$17(37.0)$
$30(37.5)$
(+)
$29(63.0)$
$50(62.5)$
Locoregional invasion
(-)
$16(34.8)$
$31(38.8)$
(+)
$30(62.5)$
$49(61.3)$

Surgical method

$\begin{array}{lll}\text { Radical } & 14(30.4) & 26(32.5) \\ \text { Palliative } & 18(39.1) & 28(35.0) \\ \text { Biopsy } & 14(30.4) & 26(32.5)\end{array}$

GBC, gallbladder cancer; SC/ASC, squamous cell/adenosquamous carcinoma; AC, adenocarcinoma; TNM, tumor-node-metastasis.

confirmed pathologically. The histological grade of GBC was based on the World Health Organization grading system (25). Tumor stage was based on the pathological tumor-node-metastasis (TNM) staging system of the American Joint Committee on Cancer (26). Surgical procedure determination was mainly based on TNM staging of GBC and patients' condition. Radical surgery included simple cholecystectomy and cholecystectomy involving a wedge resection of the gallbladder fossa with $2 \mathrm{~cm}$ non-neoplastic liver tissue. Resection of a suprapancreatic segment of the extrahepatic bile duct and extended portal lymph node dissection could also be considered based on the patient's condition. Palliative surgery was cholecystectomy with biliary drainage. Patients not suitable for surgical resection underwent surgical biopsy. The clinicopathological data are summarized in Table I. Survival information of all patients was obtained 
through letters and phone calls. The follow-up time was 2 years. Patients that survived longer than 2 years were included in the analysis as censored cases.

RNA isolation and RT-qPCR. Total RNA was isolated from fresh frozen tissues using TRIzol (Invitrogen; Thermo Fisher Scientific, Inc., Waltham, MA, USA) according to the manufacturer's protocol, and was quantified using a NanoDrop spectrophotometer (NanoDrop Technologies; Thermo Fisher Scientific, Inc., Wilmington, DE, USA). Complementary DNA (cDNA) was synthesized using a cDNA synthesis kit (Fermentas; Thermo Fisher Scientific, Inc., Pittsburgh, PA, USA). RT-qPCR was performed using SYBR PCR Green Master Mix (Applied Biosystems; Thermo Fisher Scientific, Inc.) in an ABI 7300 Real-Time PCR System (Applied Biosystems; Thermo Fisher Scientific, Inc.) according to the manufacturer's protocol. RT-qPCR was initiated by incubation for $30 \mathrm{sec}$ at $95^{\circ} \mathrm{C}$, followed by 40 cycles of $95^{\circ} \mathrm{C}$ for $10 \mathrm{sec}$ and $60^{\circ} \mathrm{C}$ for $30 \mathrm{sec}$, and a final dissociation stage of $95^{\circ} \mathrm{C}$ for $15 \mathrm{sec}, 60^{\circ} \mathrm{C}$ for $1 \mathrm{~min}$ and $95^{\circ} \mathrm{C}$ for $15 \mathrm{sec}$. Analysis of gene relative quantification was performed using the $2^{-\Delta \Delta \mathrm{Cq}}$ method (27). For each gene, RT-qPCR was performed on each sample in triplicate. Transcript levels were normalized using hydroxymethylbilane synthase (HMBS) RNA quantification. The RT-qPCR results were analyzed with SigmaStat software version 3.1 (SPSS, Inc., Chicago, IL, USA). The primers for Thyl were as follows: Forward (F), 5'-CACCACTCTGGC CATTCC-3' and reverse (R), 5'-CTCACACTTGACCAGTTT GTCTCT-3'. The primers for ITGA6 were as follows: F, 5'-CAC ATCTCCTCCCTGAGCAC-3' and R, 5'-TATCTTGCCACC CATCCTTG-3'. The primers for HMBS were as follows: $\mathrm{F}$, 5'-AGCTATGAAGGATGGGCAAC-3' and R, 5'-TTGTAT GCTATCTGAGCCGTCTA-3'.

Immunohistochemistry. Rabbit anti-Thy1 antibody (HPA003733) and rabbit anti-ITGA6 antibody (HPA012696) were purchased from Sigma-Aldrich (Merck Millipore, Darmstadt, Germany). Staining was conducted using the peroxidase-based EnVision ${ }^{\mathrm{TM}}$ Detection System (Dako North America, Inc., Carpinteria, CA, USA) according to the manufacturer's protocol. Briefly, formalin-fixed, paraffin-embedded SC/ASC and AC tissue sections (4- $\mu \mathrm{m}$ thick) on poly-L-lysine-coated slides were deparaffinized and incubated with $3 \% \mathrm{H}_{2} \mathrm{O}_{2}$ for $10 \mathrm{~min}$. Next, the sections were soaked with PBS for 5 min thrice. After 50-min incubation with the primary antibody (1:200 rabbit anti-Thy1 or 1:200 rabbit anti-ITGA6) at room temperature, the samples were incubated with a goat anti-rabbit secondary antibody conjugated with a horseradish peroxidase polymer (1:500; ab6721; Abcam, Cambridge, UK) at room temperature for $30 \mathrm{~min}$, and then developed with $\mathrm{H}_{2} \mathrm{O}_{2}$ and 3,3'-diaminobenzidine (DakoCytomation; Dako, Glostrup, Denmark). Hematoxylin was used as a counterstain. Positive controls were positive sections purchased from Fuzhou Maixin Biotech Co., Ltd. (Fuzhou, China). The negative control was designed by replacing the primary antibody with $5 \%$ fetal bovine serum (Gibco; Thermo Fisher Scientific, Inc.). The percentage of positive cells was calculated from 500 cells in 10 random fields. Cases with $\geq 25 \%$ positive cells were considered positive, while those with $<25 \%$ positive cells were considered negative.
A

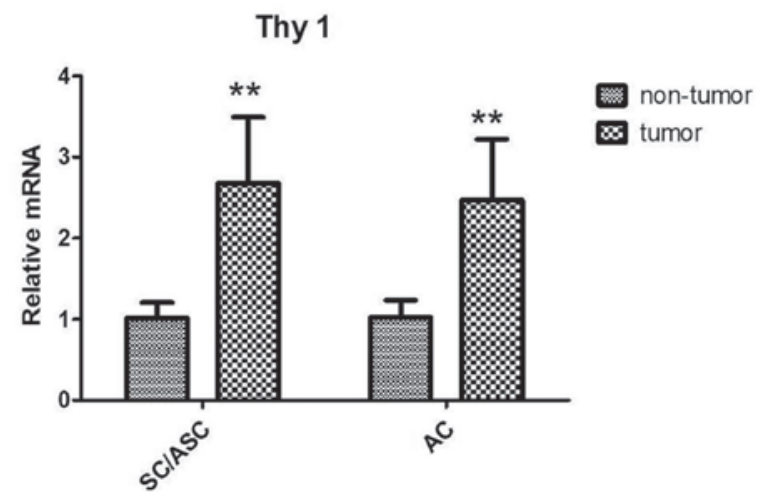

B

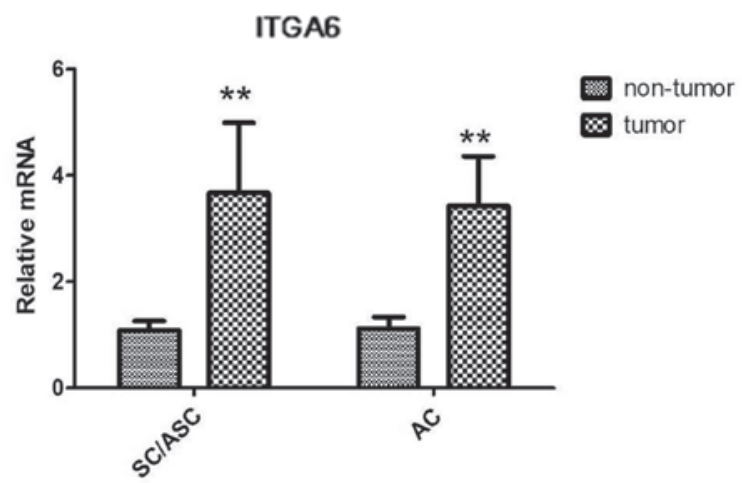

Figure 1. Thy1 and ITGA6 mRNA levels in clinical tissue samples. (A) The relative levels of Thy1 mRNA in SC/ASC and AC were analyzed by RT-qPCR. Data shown are the mean \pm SEM from experiments repeated in triplicate with three samples per treatment. ${ }^{* *} \mathrm{P}<0.001$ vs. non-tumor tissues. (B) The relative levels of ITGA6 mRNA transcripts in SC/ASC and AC were analyzed by RT-qPCR. Data shown are the mean \pm SEM from experiments repeated in triplicate with three samples per treatment. ${ }^{* *} \mathrm{P}<0.001$ vs. non-tumor tissues. SC/ASC, squamous cell/adenosquamous carcinoma; AC, adenocarcinoma; Thy1, thymus cell antigen 1; ITGA6, integrin $\alpha 6$; SEM, standard error of the mean; mRNA, messenger RNA; RT-qPCR, reverse transcription-quantitative polymerase chain reaction.

Statistics. Data were analyzed using SPSS 14.0 software (SPSS, Inc.). Paired Student's $t$-test was used to compare the messenger RNA (mRNA) levels between the tumor and non-tumor samples. The association of Thyl or ITGA6 expression with histological or clinical factors was analyzed using the $\chi^{2}$ or Fisher's exact tests. Kaplan-Meier and time series tests (log-rank test) were used for univariate survival analysis. The Cox proportional hazards model was used for multivariate analysis and for determining the $95 \%$ confidence interval. $\mathrm{P} \leq 0.05$ was considered to indicate a statistically significant difference.

\section{Results}

THY1 and ITGA6 mRNA levels in clinical tissue samples. RT-qPCR analyses of the SC/ASC and AC tissues demonstrated that both the Thy1 and ITGA6 mRNA levels were higher in tumor tissues than in the corresponding non-tumor tissues. The results demonstrated that there was a 2.6-fold upregulation in SC/ASC and a 2.4-fold upregulation in AC of Thy1 mRNA expression compared with the corresponding non-tumor tissues (both $\mathrm{P}<0.001$; Fig. 1A). Furthermore, ITGA6 mRNA levels were increased by $\sim 3.5$-fold and 3.2-fold in SC/ASC and AC tissues, respectively (both $\mathrm{P}<0.001$; Fig. 1B). However, no 

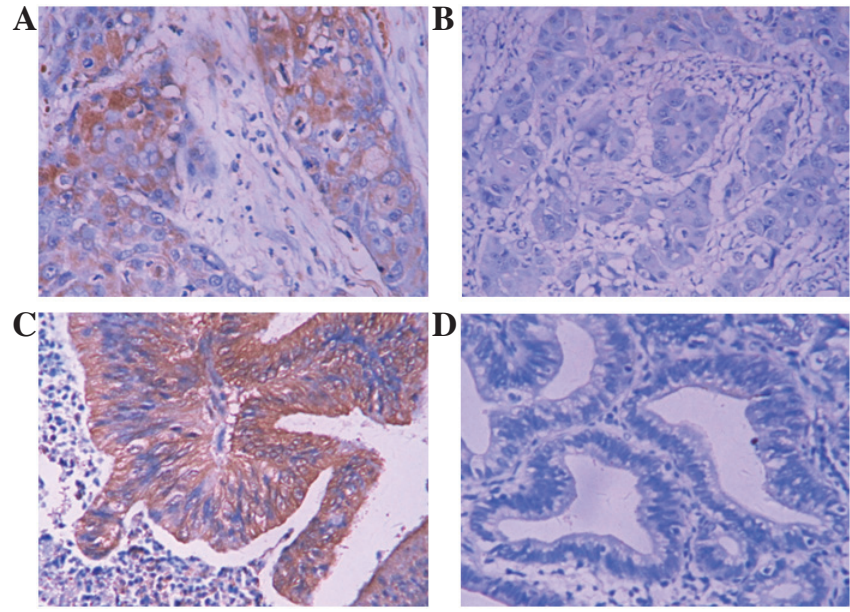

Figure 2. Immunohistochemistry of Thy1 in SC/ASC and AC (magnification, $\mathrm{x} 200$ ). The expression of Thy1 was localized mainly in the cytoplasm. (A) Positive Thyl expression in poorly differentiated SC/ASC. (B) Negative Thyl expression in moderately differentiated SC/ASC. (C) Positive Thyl expression in well differentiated AC. (D) Negative Thyl expression in well differentiated AC. SC/ASC, squamous cell/adenosquamous carcinoma; AC, adenocarcinoma; Thy1, thymus cell antigen 1.
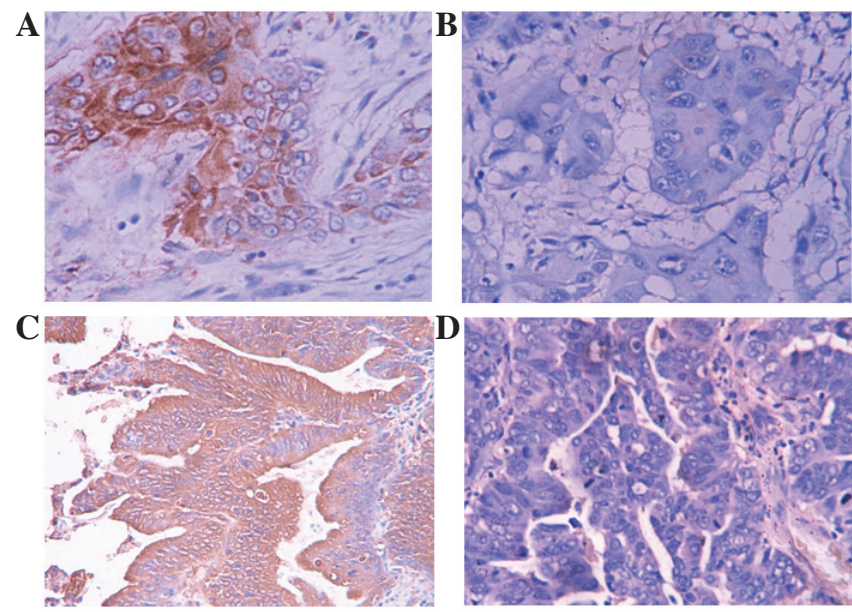

Figure 3. Immunohistochemistry of ITGA6 in SC/ASC and AC (magnification, $\mathrm{x} 200$ ). The expression of ITGA6 was localized mainly in the cytoplasm. (A) Positive ITGA6 expression in poorly differentiated SC/ASC. (B) Negative ITGA6 expression in moderately differentiated SC/ASC. (C) Positive ITGA6 expression in moderately differentiated AC. (D) Negative ITGA6 expression in moderately differentiated AC. SC/ASC, squamous cell/adenosquamous carcinoma; AC, adenocarcinoma; ITGA6, integrin $\alpha 6$.

significant differences in Thy1 or ITGA6 mRNA levels were observed between SC/ASC and AC tissues.

Evaluation of Thyl and ITGA6 expression using immunohistochemical staining. Immunohistochemical staining revealed that Thy1 and ITGA6 positive staining was mainly localized in the cytoplasm of GBC cells at different expression levels in different samples, while the majority of the non-tumor samples had negative staining (Figs. 2 and 3). The percentages of positive Thy1 and ITGA6 expression in SC/ASC and AC samples were similar (Table II).

Association of Thyl and ITGA6 expression with clinicopathological characteristics of $G B C$. To understand the
Table II. Percentage of positive Thy 1 and ITGA6 expression in SC/ASC and AC.

\begin{tabular}{ccccc}
\hline Protein & $\begin{array}{c}\text { SC/ASC, } \\
\text { no. (\%) }\end{array}$ & $\begin{array}{c}\text { AC, } \\
\text { no. (\%) }\end{array}$ & $\chi^{2}$ & P-value \\
\hline $\begin{array}{c}\text { Thy1 } \\
(-)\end{array}$ & $17(37.0)$ & $31(38.7)$ & 0.040 & 0.891 \\
$(+)$ & $29(63.0)$ & $49(61.3)$ & & \\
$\begin{array}{c}\text { ITGA6 } \\
(-)\end{array}$ & $16(34.8)$ & $30(37.5)$ & & \\
$(+)$ & $30(65.2)$ & $50(62.5)$ & & \\
\end{tabular}

Thy1, thymus cell antigen 1; ITGA6, integrin $\alpha 6$; SC/ASC, squamous cell/adenosquamous carcinoma; AC, adenocarcinoma.

significance of Thy1 and ITGA6 expression in GBC, the correlation of their protein levels with the major clinicopathological variables of the patients was evaluated. As shown in Table III, the percentages of positive Thyl and ITGA6 expression were much higher in SC/ASC cases with poor differentiation, large tumor size, lymph node metastasis and great invasiveness, and those who had undergone only biopsy, compared with cases with good differentiation, small tumor mass, no lymph node metastasis and no invasion, and those who had undergone radical resection (Thy1, $\mathrm{P}=0.045, \mathrm{P}=0.005, \mathrm{P}=0.003$ and $\mathrm{P}=0.009$ and $\mathrm{P}=0.032$, respectively, and ITGA6, $\mathrm{P}=0.029$, $\mathrm{P}=0.011, \mathrm{P}=0.009, \mathrm{P}=0.004$ and $\mathrm{P}=0.017$, respectively). Thy 1 and ITGA6 exhibited no significant association with pathological type or history of gallstones. There was higher Thy1 and ITGA6 expression in SC/ASC with advanced TNM stage than in SC/ASC with low TNM stage, although the differences were not statistically significant (both $\mathrm{P}=0.056$ ).

There was significantly higher Thy1 and ITGA6 expression in AC cases with poor differentiation, large tumor size, advanced TNM stage, lymph node metastasis and great invasiveness, and those who had undergone only biopsy than in AC cases with good differentiation, small tumor mass, low TNM stage, no lymph node metastasis and no invasion, and those who had undergone radical resection (Thy1, $\mathrm{P}=0.027, \mathrm{P}<0.001$, $\mathrm{P}=0.001, \mathrm{P}=0.003, \mathrm{P}=0.004$ and $\mathrm{P}=0.002$, respectively, and ITGA6, $\mathrm{P}=0.002, \mathrm{P}=0.003, \mathrm{P}=0.018, \mathrm{P}=0.006, \mathrm{P}=0.006$ and $\mathrm{P}=0.006$, respectively; Table IV).

Correlation between Thyl and ITGA6 expression and prognosis of $G B C$. The Kaplan-Meier survival curves for the SC/ASC patients were categorized according to their Thy1 or ITGA6 expression levels. Survival analysis revealed that the median survival rate of Thyl-positive $(\mathrm{P}<0.001)$ and ITGA6-positive $(\mathrm{P}=0.004)$ patients was significantly lower than that of patients with Thy1- and ITGA6-negative tumors (Table V and Fig. 4). Cox multivariate analysis revealed that Thy1 and ITGA6 expression, as well as differentiation, tumor size, TNM stage, invasion and surgical procedure, were negatively correlated with postoperative survival but positively correlated with mortality, suggesting that Thy1 and ITGA6 are independent risk factors for poor survival in $\mathrm{SC} / \mathrm{ASC}(\mathrm{P}=0.001$ and $\mathrm{P}=0.003$, respectively; Table VI). 
Table III. Association of Thy1 and ITGA6 expression with the clinicopathological characteristics of SC/ASC.

\begin{tabular}{|c|c|c|c|c|c|c|c|}
\hline \multirow{2}{*}{$\begin{array}{l}\text { Clinicopathological } \\
\text { characteristics }\end{array}$} & \multirow[b]{2}{*}{ Total no. } & \multicolumn{3}{|c|}{ Thy1 } & \multicolumn{3}{|c|}{ ITGA6 } \\
\hline & & Pos, no. (\%) & $\chi^{2}$ & P-value & Pos, no. (\%) & $\chi^{2}$ & P-value \\
\hline Pathological type & & & 0.735 & 0.391 & & 0.001 & 0.978 \\
\hline $\mathrm{SC}$ & 26 & $15(57.5)$ & & & $17(65.4)$ & & \\
\hline ASC & 20 & $14(70.0)$ & & & $13(65.0)$ & & \\
\hline Differentiation & & & 6.209 & 0.045 & & 6.785 & 0.029 \\
\hline Well & 16 & $7(43.8)$ & & & $7(43.8)$ & & \\
\hline Moderately & 24 & $16(66.7)$ & & & $17(70.8)$ & & \\
\hline Poorly & 6 & $6(100.0)$ & & & $6(100.0)$ & & \\
\hline $\begin{array}{l}\text { Maximum diameter } \\
\text { of tumor, cm }\end{array}$ & & & 8.065 & 0.005 & & 6.376 & 0.011 \\
\hline$\leq 3$ & 20 & $8(40.0)$ & & & $9(45.0)$ & & \\
\hline$>3$ & 26 & $21(80.8)$ & & & $21(80.8)$ & & \\
\hline Gallstones & & & 0.167 & 0.683 & & 0.027 & 0.869 \\
\hline$(-)$ & 18 & $12(66.7)$ & & & $12(66.7)$ & & \\
\hline$(+)$ & 28 & $17(60.7)$ & & & $18(64.3)$ & & \\
\hline TNM stage & & & 5.520 & 0.056 & & 5.566 & 0.056 \\
\hline $\mathrm{I}+\mathrm{II}$ & 12 & $5(41.7)$ & & & $5(41.7)$ & & \\
\hline III & 20 & $12(60.0)$ & & & $13(65.0)$ & & \\
\hline IV & 14 & $12(85.7)$ & & & $12(85.7)$ & & \\
\hline Lymph metastasis & & & 8.912 & 0.003 & & 6.870 & 0.009 \\
\hline$(-)$ & 17 & $6(35.3)$ & & & $7(41.2)$ & & \\
\hline$(+)$ & 29 & $23(79.3)$ & & & $23(79.3)$ & & \\
\hline Invasion & & & 6.870 & 0.009 & & 8.309 & 0.004 \\
\hline$(-)$ & 16 & $6(37.5)$ & & & $6(37.5)$ & & \\
\hline$(+)$ & 30 & $23(76.7)$ & & & $24(80.0)$ & & \\
\hline Surgery & & & 6.587 & 0.032 & & 8.354 & 0.017 \\
\hline Radical & 14 & $5(35.7)$ & & & $5(35.7)$ & & \\
\hline Palliative & 18 & $13(72.2)$ & & & $13(72.2)$ & & \\
\hline Biopsy & 14 & $11(78.6)$ & & & $12(85.7)$ & & \\
\hline
\end{tabular}

Thy1, thymus cell antigen 1; ITGA6, integrin $\alpha 6$; SC/ASC, squamous cell/adenosquamous carcinoma; TNM, tumor-node-metastasis; Pos, positive.

The survival rate of $\mathrm{AC}$ patients was similar to that of SC/ASC patients. Briefly, Thy1- or ITGA6-positive AC patients had poorer prognosis compared with Thyl- or ITGA6-negative AC patients (both $\mathrm{P}<0.001$; Table VII and Fig. 5). Cox multivariate analysis determined that differentiation, tumor size, TNM stage, invasion, surgical procedure, and Thyl and ITGA6 expression had a significant impact on the prognosis of AC patients (Thyl, $\mathrm{P}=0.005$ and ITGA6, $\mathrm{P}=0.003$; Table VIII).

\section{Discussion}

$\mathrm{AC}$ is the most common subtype of malignant gallbladder neoplasm, while SC and ASC are relatively rare $(1,2)$. Previous studies revealed that SC/ASC patients are older and have larger but more differentiated tumors than AC patients (28). In the present study, no significant differences were observed between AC and SC/ASC in terms of other clinicopathological characteristics (such as gender, history of cholecystolithiasis or TNM stage), biological behavior or post-surgical prognosis. Despite the improvements in the current understanding of GBC, few biomarkers have been identified that are associated with the tumorigenesis and prognosis of $\mathrm{AC}$ or SC/ASC, and the differences in terms of molecular markers between $\mathrm{AC}$ and $\mathrm{SC} / \mathrm{ASC}$ remain to be explored.

The expression of Thyl and ITGA6 in solid carcinoma was reported recently. A number of studies have revealed associations between Thyl expression and the genesis and metastasis of various tumors (4-11). Similarly, an increasing number of studies have suggested that ITGA6 expression is involved in the progression and invasion of malignant lesions $(14,15)$. Nonetheless, the expression and significance of Thyl and ITGA6 in GBC have not been addressed. The present study demonstrated that elevated Thy1 and ITGA6 levels are associated with an invasive and metastatic phenotype, as well as with 
Table IV. Association of Thy1 and ITGA6 expression with the clinicopathological characteristics of AC.

\begin{tabular}{|c|c|c|c|c|c|c|c|}
\hline \multirow{2}{*}{$\begin{array}{l}\text { Clinicopathological } \\
\text { characteristics }\end{array}$} & \multirow[b]{2}{*}{ Total no. } & \multicolumn{3}{|c|}{ Thy1 } & \multicolumn{3}{|c|}{ ITGA6 } \\
\hline & & Pos, no. (\%) & $\chi^{2}$ & P-value & Pos, no. (\%) & $\chi^{2}$ & P-value \\
\hline Differentiation & & & 7.225 & 0.027 & & 12.401 & 0.002 \\
\hline Well & 27 & $11(40.7)$ & & & $10(37.0)$ & & \\
\hline Moderately & 25 & $18(72.0)$ & & & $17(68.0)$ & & \\
\hline Poorly & 28 & $20(71.4)$ & & & $23(82.1)$ & & \\
\hline $\begin{array}{l}\text { Maximum diameter } \\
\text { of tumor, } \mathrm{cm}\end{array}$ & & & 13.065 & $<0.001$ & & 8.889 & 0.003 \\
\hline$\leq 3$ & 50 & $23(46.0)$ & & & $25(50.0)$ & & \\
\hline$>3$ & 30 & $26(86.7)$ & & & $25(83.3)$ & & \\
\hline Gallstones & & & 0.343 & 0.558 & & 0.013 & 0.908 \\
\hline$(-)$ & 42 & $27(64.3)$ & & & $26(61.9)$ & & \\
\hline$(+)$ & 38 & $22(57.9)$ & & & $24(63.2)$ & & \\
\hline TNM stage & & & 14.462 & 0.001 & & 8.560 & 0.018 \\
\hline $\mathrm{I}+\mathrm{II}$ & 21 & $7(33.3)$ & & & $8(38.1)$ & & \\
\hline III & 38 & $23(60.5)$ & & & $25(65.8)$ & & \\
\hline IV & 21 & $19(90.5)$ & & & $17(80.1)$ & & \\
\hline Lymph metastasis & & & 9.132 & 0.003 & & 10.368 & 0.006 \\
\hline$(-)$ & 30 & $12(40.0)$ & & & $12(40.0)$ & & \\
\hline$(+)$ & 50 & $37(74.0)$ & & & $38(76.0)$ & & \\
\hline Invasion & & & 8.387 & 0.004 & & 10.834 & 0.006 \\
\hline$(-)$ & 31 & $12(38.7)$ & & & $14(45.2)$ & & \\
\hline$(+)$ & 49 & $37(75.5)$ & & & $37(75.5)$ & & \\
\hline Surgery & & & 12.456 & 0.002 & & 10.376 & 0.006 \\
\hline Radical & 26 & $9(34.6)$ & & & $10(38.5)$ & & \\
\hline Palliative & 28 & $19(67.9)$ & & & $19(67.9)$ & & \\
\hline Biopsy & 26 & $21(80.8)$ & & & $21(80.8)$ & & \\
\hline
\end{tabular}

Thy1, thymus cell antigen 1; ITGA6, integrin $\alpha 6$; AC, adenocarcinoma; TNM, tumor-node-metastasis; Pos, positive.

Table V. Association between Thy 1 and ITGA6 expression and median survival rate of SC/ASC patients.

\begin{tabular}{lcccc}
\hline Protein & $\begin{array}{c}\text { Sample, } \\
\text { no. }\end{array}$ & $\begin{array}{c}\text { Median survival, } \\
\text { months (range) }\end{array}$ & $\chi^{2}$ & P-value \\
\hline Thy1 & & & 15.006 & $<0.001$ \\
$(-)$ & 17 & $14.24(6-24)$ & & \\
$(+)$ & 29 & $7.86(4-15)$ & & \\
ITGA6 & & & 8.254 & 0.004 \\
$(-)$ & 18 & $13.33(5-24)$ & & \\
$(+)$ & 28 & $8.21(4-15)$ & & \\
\hline
\end{tabular}

Thy1, thymus cell antigen 1; ITGA6, integrin $\alpha 6$; SC/ASC, squamous cell/adenosquamous carcinoma.

poor prognosis of SC/ASC and AC. The present study is, to the best of our knowledge, the first to investigate the associations between these two important biomarkers and the characteristics of GBC.
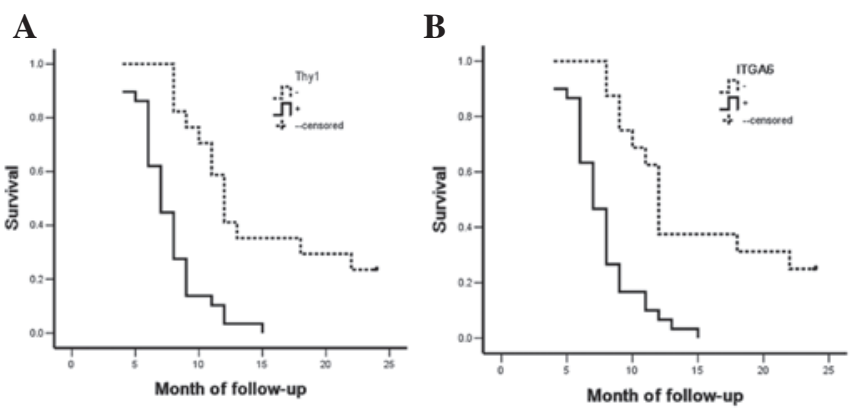

Figure 4. Thyl and ITGA6 expression and survival in patients with SC/ASC. (A) Kaplan-Meier plots of overall survival in patients with SC/ASC and with Thy1-positive and Thyl-negative expression. (B) Kaplan-Meier plots of overall survival in patients with SC/ASC and with ITGA6-positive and ITGA6-negative expression. SC/ASC, squamous cell/adenosquamous carcinoma; ITGA6, integrin $\alpha 6$; Thy1, thymus cell antigen 1.

Several studies have suggested that Thyl participates in multiple signaling cascades involving cellular adhesion, proliferation, survival and cytokine growth factor responses (29). THY1, the gene regulating Thy1 expression, is a driver of 
Table VI. Multivariate Cox regression analysis of survival rate in SC/ASC patients.

\begin{tabular}{lccrrrrrr}
\hline & & & & & & & \multicolumn{2}{c}{$95 \% \mathrm{CI}$} \\
\cline { 5 - 9 } Groups & Factors & RC & SE & Wald & P-value & RR & Lower & Upper \\
\hline Pathological type & SC/ASC & 0.496 & 0.455 & 1.188 & 0.276 & 1.642 & 0.673 & 4.006 \\
Differentiation & Well, moderately, poorly & 1.067 & 0.472 & 5.110 & 0.024 & 2.907 & 1.152 & 7.331 \\
Tumor size, cm & $\leq 3,>3$ & 2.312 & 0.637 & 13.173 & $<0.001$ & 10.095 & 2.869 & 35.181 \\
Gallstones & $(-),(+)$ & 0.645 & 0.441 & 2.139 & 0.144 & 1.906 & 0.803 & 4.524 \\
TNM stage & I+II, III, IV & 1.194 & 0.426 & 7.856 & 0.005 & 3.300 & 1.432 & 7.606 \\
Lymph metastasis & $(-),(+)$ & 1.269 & 0.583 & 4.738 & 0.030 & 3.557 & 1.135 & 11.153 \\
Invasion & $(-),(+)$ & 2.863 & 0.796 & 12.936 & $<0.001$ & 17.514 & 3.680 & 83.359 \\
Surgery & Radical, palliative, biopsy & 1.071 & 0.484 & 4.897 & 0.027 & 2.918 & 1.130 & 7.536 \\
Thy1 expression & $(-),(+)$ & 1.774 & 0.558 & 10.107 & 0.001 & 5.894 & 1.975 & 17.596 \\
ITGA6 expression & $(-),(+)$ & 1.613 & 0.539 & 8.956 & 0.003 & 5.018 & 1.745 & 14.432 \\
\hline
\end{tabular}

CI, confidence interval; SC/ASC, squamous cell/adenosquamous carcinoma; RC, regression coefficient; SE, standard error; RR, relative risk; TNM, tumor-node-metastasis; Thy1, thymus cell antigen 1; ITGA6, integrin $\alpha 6$.

Table VII. Association between Thy1 and ITGA6 expression and median survival rate of AC patients.

\begin{tabular}{|c|c|c|c|c|}
\hline Protein & $\begin{array}{c}\text { Sample, } \\
\text { no. }\end{array}$ & $\begin{array}{l}\text { Median survival, } \\
\text { months (range) }\end{array}$ & $\chi^{2}$ & P-value \\
\hline Thy1 & & & 30.138 & $<0.001$ \\
\hline$(-)$ & 31 & $15.32(7-24)$ & & \\
\hline$(+)$ & 49 & $7.84(3-19)$ & & \\
\hline ITGA6 & & & 30.992 & $<0.001$ \\
\hline$(-)$ & 30 & $15.63(4-24)$ & & \\
\hline$(+)$ & 50 & $7.80(3-16)$ & & \\
\hline
\end{tabular}

Thy1, thymus cell antigen 1; ITGA6, integrin $\alpha 6$; AC, adenocarcinoma.

invasion that has been associated with the epithelial-mesenchymal transition in breast cancer (30). Thyl also promotes migration and metastasis in melanoma (9) and hepatocarcinoma (31). Notably, Thyl has opposite functions in ovarian (10) and nasopharyngeal cancer (11). Using an extensive collection of GBC samples that included SC/ASC and AC subtypes, the present study determined that Thyl was overexpressed in GBC tumor tissues in comparison with non-tumor tissues. It was also noticed that Thyl overexpression in both SC/ASC and AC was highly correlated with poor differentiation, large tumor mass, invasion and lymph node metastasis, as well as with low rate of radical resection. Thyl expression was significantly elevated in AC with advanced TNM stage. In addition, survival was poor both in AC and in SC/ASC patients with positive Thyl expression. Therefore, Thyl may be a promising novel prognostic marker that could be helpful for guiding GBC treatment.

ITGA6 is another candidate prognostic biomarker for GBC. Tumor cell growth, differentiation and progression are greatly affected by the extracellular matrix (ECM) (17). The a6ß4 complex synergizes with specific molecules such as
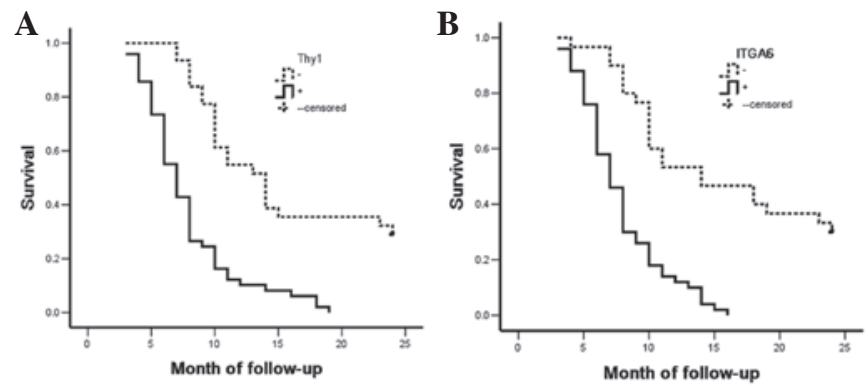

Figure 5. Thy1 and ITGA6 expression and survival in patients with AC (A) Kaplan-Meier plots of overall survival in patients with AC and with Thy1-positive and Thy1-negative expression. (B) Kaplan-Meier plots of overall survival in patients with AC and with ITGA6-positive and ITGA6-negative expression. AC, adenocarcinoma; ITGA6, integrin $\alpha 6$; Thy1, thymus cell antigen 1 .

erythroblastic leukemia viral oncogene homolog 2, epidermal growth factor receptor, receptor originated from Nantes, proto-oncogene tyrosine-protein kinase Fyn, cellular-mesenchymal to epithelial transition factor, protein kinase C, CD151 and CD9. This activates key signaling pathways involved in cancer cell invasion and migration by activating signaling molecules such as phosphatidylinositol 3-kinase (15,32). In addition, the dysregulation of ITGA6 can trigger a complex cascade of effects on the expression levels of other cell migration-related genes, including those coding for ECM and chemokine ligands and receptors. Although ITGA6 is involved in the invasion and metastasis of multiple tumors, its biological effects appear to be tissue type specific $(18,19,33-36)$. The present study observed that ITGA6 expression was significantly increased in tumor tissue compared with non-tumor tissue. It was further demonstrated that positive ITGA6 expression was significantly correlated with poor differentiation, large tumor mass, high invasion, lymph node metastasis and low rate of radical resection in both $\mathrm{SC} / \mathrm{ASC}$ and $\mathrm{AC}$. The expression of ITGA6 was significantly higher in AC with advanced TNM stage than in AC with low TNM stage. The overexpression of 
Table VIII. Multivariate Cox regression analysis of survival rate in AC patients.

\begin{tabular}{lccccccrr}
\hline & & & & & & & \multicolumn{2}{c}{$95 \%$ CI } \\
\cline { 4 - 8 } Groups & Factors & RC & SE & Wald & P-value & RR & Lower & Upper \\
\hline Differentiation & Well, moderately, poorly & 1.405 & 0.517 & 7.385 & 0.007 & 4.076 & 1.479 & 11.227 \\
Tumor size, cm & $\leq 3,>3$ & 0.994 & 0.383 & 6.736 & 0.009 & 2.702 & 1.275 & 5.724 \\
Gallstones & $(-),(+)$ & 0.325 & 0.316 & 1.058 & 0.304 & 1.384 & 0.745 & 2.571 \\
TNM stage & I+II, III, IV & 1.497 & 0.472 & 10.059 & 0.002 & 4.468 & 1.772 & 11.270 \\
Lymph metastasis & $(-),(+)$ & 1.311 & 0.486 & 7.277 & 0.007 & 3.710 & 1.431 & 9.617 \\
Invasion & $(-),(+)$ & 1.545 & 0.588 & 6.904 & 0.009 & 4.688 & 1.481 & 14.842 \\
Surgery & Radical, palliative, biopsy & 1.683 & 0.582 & 8.362 & 0.004 & 5.382 & 1.720 & 16.839 \\
Thy1 expression & $(-),(+)$ & 1.974 & 0.708 & 7.774 & 0.005 & 7.199 & 1.797 & 28.838 \\
ITGA6 expression & $(-),(+)$ & 1.913 & 0.639 & 8.962 & 0.003 & 6.773 & 1.936 & 23.699 \\
\hline
\end{tabular}

CI, confidence interval; AC, adenocarcinoma; RC, regression coefficient; SE, standard error; RR, relative risk; TNM, tumor-node-metastasis; Thy1, thymus cell antigen 1; ITGA6, integrin $\alpha 6$.

ITGA6 and its correlation with progression and poor survival suggests that ITGA6 is another candidate biological marker for identifying high-risk GBC patients who require more aggressive treatment.

Exhibiting stem cell properties, CSCs have self-renewing capacity, and are able to differentiate into heterogeneous lineages of neoplastic cells that constitute the cancer. Apart from initiating the primary tumor, CSCs also serve crucial roles in metastasis formation and cancer relapse (20). Thus, identifying and characterizing the putative CSC population in solid tumors will not only contribute to our understanding of the mechanisms of tumor initiation, metastasis and recurrence, but will also aid in the development of novel CSC-targeting therapies. Both Thy1 and ITGA6 have been used for identifying CSCs in tumors of several tissue types, including the prostate gland (4,37,38), mammary gland (39), brain (23) and colon (40). In the diseased liver, Thyl is expressed in hepatic stem cells, hepatic fibroblasts, myofibroblasts and tumor stroma, and in a small percentage of CSCs $(5,6,41-43)$. However, the vast majority of these studies focused on hepatocellular carcinoma. By contrast, the significance of ITGA6 in CSCs of liver cancer has barely been addressed. The present study investigated the role of Thyl and ITGA6 in GBC, and the results suggested that these proteins act as tumor oncogenes in both SC/ASC and $\mathrm{AC}$, and are associated with a highly invasive and metastatic phenotype. Our findings shed light on the identification of efficient CSC biomarkers in GBC. Of note, Thy1 and ITGA6 expression was predominantly located in the cytoplasm. It is possible that intracytoplasmic Thy1 and ITGA6 expression reflects overexpression of these proteins, disruption of their distribution or their degradation in neoplastic cells.

Various limitations of the present study should be considered. First, although it was demonstrated that Thy1 and ITGA6 are associated with GBC progression, the underlying mechanisms by which these proteins regulate cancer behavior were not explored. This is an area worthy to be explored in the future. Second, the efficiency of Thyl and ITGA6 as CSC biomarkers in GBC was not investigated. A deeper understanding of this could be attained using an in vitro cell model. Overall, our results demonstrate that Thy1 and ITGA6 expression is higher in GBC tumor samples than in non-tumor samples, whereas Thyl and ITGA6 expression in SC/ASC and $\mathrm{AC}$ is similar. Furthermore, overexpression of Thy1 and ITGA6 can be considered a novel and important risk factor for $\mathrm{SC} / \mathrm{ASC}$ and $\mathrm{AC}$ invasion, metastasis and poor prognosis. In conclusion, the results of the present study suggest that Thy1 and ITGA6 function as oncogenes in GBC invasion, metastasis and prognosis.

\section{Acknowledgements}

The authors are grateful to the members of the Research Laboratory of Hepatobiliary Diseases, The Second Xiangya Hospital, Central South University (Changsha, China), who have provided helpful and critical discussions during the preparation and writing of the present manuscript.

\section{References}

1. Ootani T, Shirai Y, Tsukada K and Muto T: Relationship between gallbladder carcinoma and the segmental type of adenomyomatosis of the gallbladder. Cancer 69: 2647-2652, 1992.

2. Kim WS, Jang KT, Choi DW, Choi SH, Heo JS, You DD and Lee HG: Clinicopathologic analysis of adenosquamoussquamous cell carcinoma of the gallbladder. J Surg Oncol 103: 239-242, 2011.

3. Rege TA and Hagood JS: Thy-1 as a regulator of cell-cell and cell-matrix interactions in axon regeneration, apoptosis, adhesion, migration, cancer, and fibrosis. FASEB J 20: 1045-1054, 2006.

4. True LD, Zhang H, Ye M, Huang CY, Nelson PS, von Haller PD, Tjoelker LW, Kim JS, Qian WJ, Smith RD, et al: CD90THY1 is overexpressed in prostate cancer-associated fibroblasts and could serve as a cancer biomarker. Mod Pathol 23: 1346-1356, 2010.

5. Sukowati CH, Anfuso B, Torre G, Francalanci P, Crocè LS and Tiribelli C: The expression of CD90Thy-1 in hepatocellular carcinoma: An in vivo and in vitro study. PLoS One 8: e76830, 2013.

6. Lingala S, Cui YY, Chen X, Ruebner BH, Qian XF, Zern MA and Wu J: Immunohistochemical staining of cancer stem cell markers in hepatocellular carcinoma. Exp Mol Pathol 89: 27-35, 2010.

7. Lu JW, Chang JG, Yeh KT, Chen RM, Tsai JJ and Hu RM: Overexpression of Thy1CD90 in human hepatocellular carcinoma is associated with HBV infection and poor prognosis. Acta Histochem 113: 833-838, 2011. 
8. Johansson I, Ringnér M and Hedenfalk I: The landscape of candidate driver genes differs between male and female breast cancer. PLoS One 8: e78299, 2013.

9. Saalbach A, Wetzel A, Haustein UF, Sticherling M, Simon JC and Anderegg U: Interaction of human Thy-1 (CD 90) with the integrin alphavbeta3 (CD51CD61): An important mechanism mediating melanoma cell adhesion to activated endothelium. Oncogene 24: 4710-4720, 2005.

10. Abeysinghe HR, Pollock SJ, Guckert NL, Veyberman Y, Keng P, Halterman M, Federoff HJ, Rosenblatt JP and Wang N: The role of the THY1 gene in human ovarian cancer suppression based on transfection studies. Cancer Genet Cytogenet 149: 1-10, 2004

11. Lung HL, Cheung AK, Cheng Y, Kwong FM, Lo PH, Law EW, Chua D, Zabarovsky ER, Wang N, Tsao SW, et al: Functional characterization of THY1 as a tumor suppressor gene with antiinvasive activity in nasopharyngeal carcinoma. Int J Cancer 127 304-312, 2010.

12. Belkin AM and Stepp MA: Integrins as receptors for laminins. Microsc Res Tech 51: 280-301, 2000.

13. Lowell CA and Mayadas TN: Overview: Studying integrins in vivo. Methods Mol Biol 757: 369-397, 2012.

14. Carloni V, Mazzocca A, Pantaleo P, Cordella C, Laffi G and Gentilini P: The integrin, alpha6beta1, is necessary for the matrix-dependent activation of FAK and MAP kinase and the migration of human hepatocarcinoma cells. Hepatology 34 42-49, 2001.

15. Yoon SO, Shin S and Lipscomb EA: A novel mechanism for integrin-mediated ras activation in breast carcinoma cells: The alpha6beta4 integrin regulates ErbB2 translation and transactivates epidermal growth factor receptorErbB2 signaling. Cancer Res 66: 2732-2739, 2006.

16. He J, Liu Y, Zhu T, Zhu J, Dimeco F, Vescovi AL, Heth JA, Muraszko KM, Fan X and Lubman DM: CD90 is identified as a candidate marker for cancer stem cells in primary high-grade gliomas using tissue microarrays. Mol Cell Proteomics 11: M111, 2012.

17. Cariati M, Naderi A, Brown JP, Smalley MJ, Pinder SE, Caldas C and Purushotham AD: Alpha-6 integrin is necessary for the tumourigenicity of a stem cell-like subpopulation within the MCF7 breast cancer cell line. Int J Cancer 122: 298-304, 2008.

18. Yamamoto H, Masters JR, Dasgupta P, Chandra A, Popert R Freeman A and Ahmed A: CD49f is an efficient marker of monolayer- and spheroid colony-forming cells of the benign and malignant human prostate. PLoS One 7: e46979, 2012.

19. Pascal LE, Goo YA, Vêncio RZ, Page LS, Chambers AA, Liebeskind ES, Takayama TK, True LD and Liu AY: Gene expression downregulation in CD90+ prostate tumor-associated stromal cells involves potential organ-specific genes. BMC Cancer 9: 317, 2009.

20. Kopper L and Hajdú M: Tumor stem cells. Pathol Oncol Res 10: 69-73, 2004.

21. Martin TA and Jiang WG: Evaluation of the expression of stem cell markers in human breast cancer reveals a correlation with clinical progression and metastatic disease in ductal carcinoma. Oncol Rep 31: 262-272, 2014

22. Yang W, Yan HX, Chen L, Liu Q, He YQ, Yu LX, Zhang SH, Huang DD, Tang L, Kong XN, et al: Wntbeta-catenin signaling contributes to activation of normal and tumorigenic liver progenitor cells. Cancer Res 68: 4287-4295, 2008

23. Haraguchi N, Ishii H, Mimori K, Ohta K, Uemura M, Nishimura J, Hata T, Takemasa I, Mizushima T, Yamamoto $\mathrm{H}$, et al: CD49f-positive cell population efficiently enriches colon cancer-initiating cells. Int J Oncol 43: 425-430, 2013.

24. Hermann PC, Huber SL, Herrler T, Aicher A, Ellwart JW, Guba M, Bruns CJ and Heeschen C: Distinct populations of cancer stem cells determine tumor growth and metastatic activity in human pancreatic cancer. Cell Stem Cell 1: 313-323, 2007.

25. Khan SA, Davidson BR, Goldin R, Pereira SP, Rosenberg WM Taylor-Robinson SD, Thillainayagam AV, Thomas HC, Thursz MR and Wasan H; British Society of Gastroenterology: Guidelines for the diagnosis and treatment of cholangiocarcinoma: Consensus document. Gut 51 (Suppl 6): 7-9, 2002.
26. Sobin LH, Gospodarowicz MK and Wittekind C (eds): International Union Against Cancer (UICC) TNM Classification of Malignant Tumors. 7th edition. Wiley-Liss, New York, NY, 2009.

27. Livak KJ and Schmittgen TD: Analysis of relative gene expression data using real-time quantitative PCR and the 2(-Delta Delta C(T)) method. Methods 25: 402-408, 2001.

28. Li QL, Yang ZL, Liu JQ and Miao XY: Expression of CDX2 and hepatocyte antigen in benign and malignant lesions of gallbladder and its correlation with histopathologic type and clinical outcome. Pathol Oncol Res 17: 561-568, 2011.

29. Rege TA and Hagood JS: Thy-1, a versatile modulator of signaling affecting cellular adhesion, proliferation, survival, and cytokinegrowth factor responses. Biochim Biophys Acta 1763: 991-999, 2006.

30. Taube JH, Herschkowitz JI, Komurov K, Zhou AY, Gupta S, Yang J, Hartwell K, Onder TT, Gupta PB, Evans KW, et al: Core epithelial-to-mesenchymal transition interactome gene-expression signature is associated with claudin-low and metaplastic breast cancer subtypes. Proc Natl Acad Sci USA 107: 15449-15454, 2010.

31. Cheng BQ, Jiang Y, Li DL, Fan JJ and Ma M: Upregulation of thy-1 promotes invasion and metastasis of hepatocarcinomas. Asian Pac J Cancer Prev 13: 1349-1353, 2012.

32. Lu P, Weaver VM and Werb Z: The extracellular matrix: A dynamic niche in cancer progression. J Cell Biol 196: 395-406, 2012.

33. Guo W and Giancotti FG: Integrin signalling during tumour progression. Nat Rev Mol Cell Biol 5: 816-826, 2004

34. Tian B, Li Y, Ji XN, Chen J, Xue Q, Ye SL, Liu YK and Tang ZY: Basement membrane proteins play an active role in the invasive process of human hepatocellular carcinoma cells with high metastasis potential. J Cancer Res Clin Oncol 131: 80-86, 2005

35. Ports MO, Nagle RB, Pond GD and Cress AE: Extracellular engagement of alpha6 integrin inhibited urokinase-type plasminogen activator-mediated cleavage and delayed human prostate bone metastasis. Cancer Res 69: 5007-5014, 2009.

36. Kalogeropoulou M, Voulgari A, Kostourou V, Sandaltzopoulos R, Dikstein R, Davidson I, Tora L and Pintzas A: TAF4b and Junactivating protein-1 collaborate to regulate the expression of integrin alpha6 and cancer cell migration properties. Mol Cancer Res 8: 554-568, 2010.

37. Germain M, De Arcangelis A, Robinson SD, Baker M, Tavora B, D'Amico G, Silva R, Kostourou V, Reynolds LE, Watson A, et al: Genetic ablation of the alpha 6-integrin subunit in Tie1Cre mice enhances tumour angiogenesis. J Pathol 220: 370-381, 2010

38. Yamakawa N, Kaneda K, Saito Y, Ichihara E and Morishita K: The increased expression of integrin alpha6 (ITGA6) enhances drug resistance in EVI1 (high) leukemia. PLoS One 7: e30706, 2012.

39. Vassilopoulos A, Chisholm C, Lahusen T, Zheng H and Deng CX: A critical role of CD29 and CD49f in mediating metastasis for cancer-initiating cells isolated from a Brcal-associated mouse model of breast cancer. Oncogene 33: 5477-5482, 2014.

40. Lathia JD, Gallagher J, Heddleston JM, Wang J, Eyler CE, Macswords J, Wu Q, Vasanji A, McLendon RE, Hjelmeland AB and Rich JN: Integrin alpha 6 regulates glioblastoma stem cells. Cell Stem Cell 6: 421-432, 2010

41. Herrera MB, Bruno S, Buttiglieri S, Tetta C, Gatti S, Deregibus MC, Bussolati B and Camussi G: Isolation and characterization of a stem cell population from adult human liver. Stem Cells 24: 2840-2850, 2006.

42. Dan YY, Riehle KJ, Lazaro C, Teoh N, Haque J, Campbell JS and Fausto N: Isolation of multipotent progenitor cells from human fetal liver capable of differentiating into liver and mesenchymal lineages. Proc Natl Acad Sci USA 103: 9912-9917, 2006.

43. Yang ZF, Ngai P, Ho DW, Yu WC, Ng MN, Lau CK, Li ML, Tam KH, Lam CT, Poon RT and Fan ST: Identification of local and circulating cancer stem cells in human liver cancer. Hepatology 47: 919-928, 2008. 